\title{
Sentimentos de mulheres jovens frente ao diagnóstico de câncer de mama feminino
}

\author{
Feelings of young women facing diagnosis of female breast cancer
}

Isabella Barros Rabelo Gontijo ${ }^{1}$, Cintia Bragheto Ferreira²

\section{RESUMO}

Objetivo: Identificar e descrever os sentimentos de mulheres jovens a partir do diagnóstico de câncer de mama feminino, bem como apresentar as estratégias construídas por essas mulheres para lidarem com as repercussões dessa notícia.

Materiais e Métodos: Pesquisa qualitativa, com entrevistas semiestruturadas, que envolveu três mulheres com a confirmação do diagnóstico. A análise das entrevistas utilizou o referencial construcionista social, o que resultou na elaboração das seguintes temáticas: ser mulher; o diagnóstico; o tratamento e suas implicações.

Resultados: Os resultados mostraram que o diagnóstico desperta o medo da morte e choque, os quais são amenizados preferencialmente na relação com a religiosidade. Além disso, ocorrem repercussões na autonomia e alterações na feminilidade.

Conclusão: Propõe-se a relevância da assistência interdisciplinar direcionada a essa população, bem como a continuidade dos estudos para essa faixa etária.

Palavras-chave: neoplasias da mama; diagnóstico; feminilidade.

\begin{abstract}
Objective: To identify and describe the feelings of young women from been diagnosed with breast cancer, as well as to present strategies built by these women to deal with this news.

Materials and Methods: Qualitative research carried out through the semi-structured interview with three women who had received a breast cancer diagnosis. The interviews were analyzed through social constructionist perspective, which resulted on the construction of these following topics: to be woman; diagnosis; treatment and its implications.

Results: The results showed that diagnosis provokes fear from death and shock, which are reduced especially on the religious' relationship. Further, it provokes changes in the autonomy and femininity.

Conclusion: This study proposes the relevance of interdisciplinary assistance guided for this population, as well as the continuity of studies for this age group.
\end{abstract}

Keywords: breast neoplasms; diagnosis; femininity.

${ }^{1}$ Psicóloga. Residente no Programa de Residência Multiprofissional em Atenção Oncológica, Hospital Universitário de Brasília (UnB). ${ }^{2}$ Psicóloga. Doutora em Enfermagem em Saúde Pública pela Escola de Enfermagem de Ribeirão Preto da Universidade de São Paulo (USP). Professora adjunta do curso de Psicologia da Universidade Federal de Goiás (UFG), Campus Jataí. 


\section{INTRODUÇÃo}

Dados do Instituto Nacional de Câncer apresentam a estimativa de 57.120 casos novos de câncer de mama para o ano de $2014^{1}$. A idade continua sendo o principal fator de risco para o câncer de mama, cuja incidência aumenta mais frequentemente a partir dos 50 anos de idade. Além disso, fatores relacionados à vida reprodutiva da mulher, como gestação após os 30 anos, história familiar de câncer de mama e exposição à radiação ionizante ${ }^{2}$.

No Brasil atualmente verificam-se avanços tanto no combate quanto na prevenção do câncer, observados tanto em investimentos financeiros quanto na união de diversos pesquisadores em projetos integrados ${ }^{3}$, e mesmo assim, o câncer de mama ainda é o tipo de neoplasia que mais acomete as mulheres brasileiras. A prevenção primária ainda não é totalmente possível em razão da variação de fatores de risco e das características genéticas que estão envolvidas na sua etiologia. Entretanto, sabe-se que a prática de atividade física e a alimentação saudável, bem como a manutenção do peso corporal estão associadas a um menor risco de desenvolver esse tipo de câncer ${ }^{2}$.

A reação ao diagnóstico de câncer depende das características de personalidade da pessoa, do nível da doença, das variáveis de tratamento e de fatores ambientais $^{4}$. Em meio ao desequilíbrio causado pelo adoecer, as mulheres se engajam em um processo de enfrentamento que pode auxiliar no percurso do tratamento da doença, sendo o suporte religioso/espiritual uma forma importante para minimizar o sofrimento experimentado ${ }^{5,6}$.

O primeiro contato com a doença gera angústia, tanto nas mulheres como nos familiares, podendo ser acompanhada, por sintomas depressivos ${ }^{7}$, clima de estresse constante, frustração na realização de desejos e necessidades, perda do sentimento de autoestima, perda da privacidade e liberdade, perda da identidade ${ }^{8}$, alterações na qualidade de vida, constantes mudanças nas relações interpessoais, dentre outras alterações ${ }^{9}$. Essa desorganização gerada pelo adoecer é refletida na dificuldade relatada pelas mulheres em desempenhar os papéis que permeiam suas interações ${ }^{10,11}$, que vão desde a mulher mãe à mulher profissional.
O adoecer por câncer de mama implica ainda o percurso de um tratamento doloroso, podendo ser necessário um procedimento cirúrgico juntamente com terapia adjuvante (quimioterapia, radioterapia, hormonioterapia, imunoterapia), utilizados de acordo com as necessidades particulares de cada mulher ${ }^{12,13}$. Além disso, o medo da recidiva também acompanha as mulheres que tiveram câncer de mama, gerando ansiedade, sofrimento e pensamentos intrusivos ${ }^{14}$.

As mulheres idosas se relacionam com o adoecer por câncer de mama e limitações, impostas pelo tratamento, voltadas para o trabalho doméstico, demonstrando assim que o lugar feminino para essa população parece estar constituído pelo discurso do ser mulher tradicional, fundado no modelo de família burguesa do século $\mathrm{XIX}^{15,16}$. Além disso, as mulheres mais velhas, ao se depararem com a doença, sentem um grande susto, choque e medo da morte ${ }^{17}$. Para essas pessoas, o adoecer representa provação, morte ${ }^{17,18,19}$ e ameaça à feminilidade ${ }^{15}$, podendo despertar ainda sentimentos como a revolta e a ansiedade ${ }^{17}$.

A vivência do câncer de mama por mulheres jovens é encontrada apenas em estudos internacionais, demonstrando que essa população apresenta grande ansiedade a partir do diagnóstico da doença ${ }^{20}$, resultados piores de qualidade de vida e depressão quando comparadas às mulheres mais velhas com câncer de mama. Além disso, preocupações com a menopausa precoce e infertilidade são comuns ${ }^{21,22}$ e contribuem significativamente para o nível de angústia experimentado ao final do tratamento do câncer, sendo que essas mesmas mulheres jovens também apresentam problemas como ganho de peso e inatividade física ${ }^{22}$.

A partir desse quadro da literatura, verifica-se a lacuna de estudos que contemplem a experiência pessoal de mulheres jovens que recebem o diagnóstico de câncer de mama, com aspectos socioculturais ${ }^{23}$ específicos como 0 de mulheres residentes em municípios de pequeno porte distantes dos grandes centros urbanos brasileiros, sendo este o interesse desta investigação. No presente estudo, a compreensão do diagnóstico de câncer de mama feminino para mulheres jovens esteve ancorada na perspectiva 
construcionista social, a qual aponta que as pessoas constroem em suas relações sociais sentidos para os acontecimentos que as circundam, de forma histórica e culturalmente localizadas ${ }^{24}$, por meio da linguagem que está sempre em ação nos processos dialógicos. Trabalhar no campo do construcionismo social requer a retomada da história, visando a compreensão da construção social dos conceitos que empregamos para darmos sentido ao que nos circunda ${ }^{25}$.

Historicamente o câncer é associado a uma doença inglória, contraída por meio da sujeira do corpo e da alma ${ }^{19}$, compreendida como um castigo justo e necessário para a purificação de pessoas imorais, além de uma enfermidade invasora, geradora de sofrimento, perdas $^{26,27}$, tristeza, dor ${ }^{18}$ e morte ${ }^{18,28}$. Associada a situações desagradáveis, como a violência ${ }^{29}$ e culpabilização do doente por sua enfermidade, por não ter dado vazão às suas emoções ${ }^{27}$.

Neste trabalho parte-se da perspectiva de que ser mulher é uma construção social, cujos significados estão presentes no contexto histórico-social e cultural direcionando modos de ser e agir. Segundo Magalhães ${ }^{10}$ os papéis sociais e os papéis dentro da família fazem parte de acordos interacionais construídos nos processos de socialização, são consensos individuais e sociais, na interação entre indivíduo, família e sociedade e em meio a essa interação surge, a mulher esposa, mãe, profissional, dentre outros papéis.

Após uma longa e constante luta histórica, a mulher tem criado novos significados para sua identidade feminina. Entretanto, não foi sempre assim, apenas a partir dos anos de 1960 é que a mulher consegue libertar-se e sair da esfera meramente privada da família partindo para a profissionalização, na busca de direitos civis iguais aos dos homens ${ }^{30}$. Atualmente a ascensão social da mulher é maior, visto que cada vez mais ela tem se inserido no espaço público e no mundo do trabalho, por meio da qualificação para o desempenho de suas atividades profissionais, ou seja, percebe-se uma condição feminina que valoriza seu trabalho e sua independência ${ }^{31}$. Contudo, as mulheres trabalhadoras podem ser descritas como pessoas sobrecarregadas, pois acumulam uma identidade voltada tanto para o trabalho quanto para a família, com a permanência de responsabilidades domésticas, cuidados com os filhos e outros familiares ${ }^{32}$.

Diante do exposto, a perspectiva construcionista social, assim como os sentidos construídos para o ser mulher e para o câncer ao longo da história, foram utilizados como referenciais para 0 alcance dos objetivos propostos neste trabalho, que foram: identificar e descrever os sentimentos despertados, nas participantes do estudo, a partir da confirmação do câncer de mama, bem como as saídas construídas, pelas entrevistadas, para lidarem com esse diagnóstico, buscando sua desfamiliarização e problematização ${ }^{25}$.

\section{MATERIAIS E MÉTODOS}

O estudo realizado foi de abordagem qualitativa, com o propósito de descrever e analisar os significados que mulheres jovens acometidas por câncer de mama constroem para lidar com esse diagnóstico, entendendo essas saídas enquanto um processo que tenta compreender as pessoas em sua vida cotidiana ${ }^{33}$.

\section{Instituição e Participantes}

As participantes deste estudo foram contatadas em um Núcleo Regional de Combate ao Câncer ${ }^{34}$ localizado em um município do interior goiano, caracterizado como uma associação civil, assistencial, de direito privado e não governamental. Atualmente a instituição conta com aproximadamente 900 pessoas cadastradas, sendo que, no período de 18 anos de registro, encontraram-se 334 mulheres registradas entre o diagnóstico positivo e a prevenção do câncer de mama. Dentre todas as mulheres cadastradas com câncer de mama, foram escolhidas as mulheres abaixo dos 50 anos de idade, o que resultou na escolha de 3 mulheres, sendo a mais jovem com 31 anos e a mais velha com 37 anos, as quais compuseram a amostra desta investigação.

\section{PROCEDIMENTOS}

O estudo foi submetido a um Comitê de Ética em Pesquisa e aprovado (parecer $n^{0}$ 100/12). Posteriormente à aprovação foi feito o convite às mulheres para a participação na pesquisa. Com cada uma das participantes houve um momento prévio para a 
explicação do estudo, com a leitura e assinatura do Termo de Consentimento Livre e Esclarecido, seguido pela realização da entrevista.

As entrevistas utilizadas foram do tipo semiestruturada e realizadas individualmente nas dependências do Núcleo, apenas com a presença da pesquisadora e da entrevistada. As perguntas versaram sobre os dados sócio-demográficos das participantes, sobre o diagnóstico do câncer de mama, assim como as formas de lidar com a confirmação da doença e suas repercussões.

As entrevistas tiveram duração média de 60 minutos, foram gravadas e transcritas na íntegra. Posteriormente foram lidas de forma exaustiva para que os temas mais relevantes emergissem das falas das participantes ${ }^{35}$, com curiosidade e abertura para a multiplicidade e o diferente $^{36}$, o que resultou na construção de três grandes temáticas, que descrevem e analisam as repercussões do diagnóstico de câncer de mama para as entrevistadas.

As temáticas construídas foram analisadas ancoradas na abordagem construcionista social, buscando assim compreender os discursos das entrevistadas enquanto artefatos sociais produzidos historicamente e culturalmente de forma coletiva ${ }^{24}$.

\section{RESULTADOS E DISCUSSÃO}

Neste espaço são apresentadas as participantes do estudo, assim como as temáticas que emergiram das entrevistas, sendo elas: ser mulher; o diagnóstico; o tratamento e suas implicações.

\section{Gratidão}

Casada, 31 anos, auxiliar de serviços gerais, ensino médio completo, define sua classe social como "trabalhadora" e não apresentava recidiva no momento de realização da entrevista. Foi submetida ao seguinte tratamento: quimioterapia, seguida pela cirurgia (mastectomia radical) e quimioterapia. Mudou-se de Minas Gerais com os três filhos para acompanhar o marido a trabalho, tinha planos de retornar para Minas Gerais, mas o descobrir-se com um nódulo no seio e o acesso mais fácil ao tratamento em Goiás a fizeram ficar. Sempre trabalhou fora e contribuiu financeiramente em casa. Demonstra muito amor e gratidão pelo cuidado integral provido pelo marido.

\section{Esperança}

Viúva, 37 anos, do lar, ensino fundamental incompleto, define sua classe social como baixa, é goiana, mãe de duas filhas e no momento de realização da entrevista estava em tratamento de uma recidiva na axila homolateral à mama operada. Foi submetida ao seguinte tratamento: quimioterapia, cirurgia (quadrantectomia com esvaziamento axilar) e radioterapia, sendo que já vivenciou o câncer mesmo antes de adoecer, pois seu marido faleceu com câncer no fígado. O fato de se deparar com a doença novamente trouxe muito medo, entretanto, mostra-se esperançosa quanto ao tratamento e sua recuperação, pois relata que assim será possível cuidar de suas filhas.

Força

Casada, 36 anos, do lar, ensino médio incompleto e define sua classe social como baixa, sendo que no momento de realização da entrevista não apresentava recidiva. Veio do Pará, com sua filha, para Goiás para acompanhar o marido. Foi submetida ao seguinte tratamento: quimioterapia, cirurgia (mastectomia radical) e radioterapia. Força apresenta uma grande dificuldade de movimentação no braço homolateral à cirurgia. Atualmente não consegue realizar as atividades domésticas que gosta, mas mesmo em meio às dificuldades consegue transmitir persistência e força em sua história.

\section{Ser mulher}

Atualmente presencia-se um processo constituído pela saída feminina da esfera meramente privada da família, buscando objetivos profissionais, construindo maior independência ${ }^{30}$ e qualificação em atividades profissionais ${ }^{31}$. Pode-se constatar isso ao perguntar às entrevistadas o que significava para elas ser mulher.

"Acredito que é ter a oportunidade de tá fazendo 
alguma coisa, trabalhar fora! (Gratidão).”

"Cuidava da casa, hoje não posso fazer mais nada (Força)."

"Ser mãe é ser mulher (Esperança)."

Ser mulher para as participantes deste estudo, apesar de serem mulheres jovens, ainda parece reproduzir o modelo de mulher prescrito no modelo de conjugalidade tradicional, o qual aponta que ser mulher está associado ao cuidado da casa, dos filhos e do marido ${ }^{15,16}$. Por outro lado, parece que as entrevistadas estão vivenciando também um acúmulo de funções, com uma identidade voltada tanto para o trabalho como para a família ${ }^{32}$. Além disso, ao relatarem que ser mulher é trabalhar fora e ser independente representa o lugar contemporâneo feminino ${ }^{30}$.

Já o câncer de mama foi considerado pelas entrevistadas como um empecilho para a concretização da independência feminina, associado por elas ao mundo do trabalho.

"É muito bom, ser muié, cuidar da saúde, e agora ficou difícil, num posso fazer mais nada! (...) A única coisa que posso fazer mesmo é tomar banho (Força)."

"O que eu fico mais triste não é por causa da doença, é pelo fato deu não poder fazer tudo que eu fazia antes (Gratidão)."

Nessa temática é possível perceber que o encontro com o câncer de mama despertou nas participantes o questionamento sobre o que é ser mulher e trouxe limitações à continuação de alguns de seus papéis, principalmente das entrevistadas Força e Gratidão, atividades que elas consideram importantes, e que são centrais em suas vidas, precisaram ser reformuladas ou até mesmo abandonadas.

\section{O diagnóstico}

A mulher que recebe o diagnóstico de câncer de mama é colocada diante de uma doença estigmatizante que implica em perdas na qualidade de vida e mudanças constantes, seja em suas relações sociais, familiares, com ela mesma ${ }^{9,20,23}$ e comumente acompanhada por sintomas depressivos ${ }^{7,23}$. O sofrimento vem do caráter incurável e da ideia de morte ${ }^{9}$, repercutindo na dificuldade em desempenhar os papéis de mulher, mãe, esposa, profissional, dentre outros $^{11}$.

As entrevistadas, ao serem indagadas sobre seus sentimentos frente à confirmação do diagnóstico, relataram seu sofrimento em relação ao câncer, associado à morte e a um choque, mas também demonstraram fé em sua recuperação.

“(...) eu senti muito medo! Um pavor! Eu achava que eu ia morrer, eu só pensava nisso (Gratidão)."

"Uma doença dessa quando cê recebe assim cê pensa logo que vai morrer (...) aí eu fiquei sem chão, eu pensei assim eu tenho que lutar pelas minhas filhas, pra mim sobreviver (...) (Esperança)."

"Eu fiquei assim (...). Vou morrer! A primeira coisa que a gente pensa. No começo foi um choque (Força)."

Gratidão, ancorada na prerrogativa de que o câncer de mama acomete apenas mulheres mais velhas ${ }^{2}$, não conseguia acreditar na confirmação do diagnóstico:

"Não conseguia acreditar, porque às vezes você vê acontecendo com os outros mas não imagina nunca que vai acontecer com a gente, até onde eu sei é muito raro uma mulher de trinta anos com câncer de mama, nossa, foi um susto muito grande (Gratidão)."

O câncer de mama, além de trazer diferenças na relação da mulher consigo mesma, que são expressadas em mudanças de autoimagem ${ }^{23}$, autoestima e perda da feminilidade ${ }^{4}$, também pode promover mudanças mais ampliadas, como de lugar para morar.

"Eu perdi até minha vaidade. Eu esqueço de usar, tudo! Depois, parece que a cabeça da gente fica focada só naquilo. Nunca imaginei, meus planos não era ficar aqui, eu ia embora (Gratidão)."

Em meio a tantas mudanças, as entrevistadas apresentaram preferencialmente a relação com o universo religioso/espiritual como estratégia de 
enfrentamento para lidarem com 0 sofrimento despertado pela chegada do câncer.

"Eu só pensei assim com fé em Deus, eu vou ficar boa e fui tratar. Sou crente da Assembléia de Deus, Deus tem abençoado, eu tenho muita fé (Força)."

"Graças a Deus eu tô levando, de uma maneira melhor, depois que eu comecei o tratamento. É só eu, Deus na frente, eu, meu marido e meus filhos (Gratidão)."

"Mais animada porque eu já passei por tanta coisa e eu tô bem graças a Deus (Esperança)."

A relação entre a religiosidade e a saúde/doença auxilia as pessoas a administrarem melhor a vivência da enfermidade ${ }^{5,6}$, ajudando na aceitação da doença, no processo de cura ${ }^{37}$ e no vislumbre de um futuro apesar do sofrimento vivido ${ }^{25}$. Observa-se, portanto, que a religiosidade aparece como um suporte importante para reduzir o sofrimento gerado pela enfermidade, o que já está na literatura menos para o grupo ora analisado.

\section{O tratamento e suas implicações}

Depois que a mulher recebe a confirmação do câncer de mama ela então passa para a fase do tratamento, composto geralmente pela cirurgia que pode ou não ser acompanhada e/ou precedida por quimioterapia, radioterapia, hormonioterapia e imunoterapia ${ }^{12,13}$.

Nos relatos das participantes é possível identificar algumas implicações do tratamento, como repercussões no cuidado da família, com prejuízos no trabalho, um intenso sofrimento ocasionado pelo deslocamento até a cidade que oferece as terapêuticas para o câncer, além do medo.

"Eu tenho medo do tratamento, mais medo do que da doença, tem hora que só na primeira quimioterapia que eu fiz dá vontade de desistir (Gratidão)."

"Quem tá passando por isso, é difícil (Esperança)."

Nas falas de Gratidão e Esperança percebe-se que a repetição do ciclo quimioterápico representa algo amedrontador e temeroso, pois estão relacionados à possibilidade da morte ${ }^{28}$. No decorrer da entrevista,
Gratidão, ainda, relata significados sobre o tratamento do câncer de mama construídos a partir do contato com a doença em situações anteriores, assim como Esperança, cujo marido havia falecido em decorrência do câncer.

"Tem uma moça lá na minha terra (...), ela já tinha falecido, com dezoito anos, com câncer de mama. Aí quando eu lembrei dela, nossa senhora! Aquilo me apavorou mais ainda (Gratidão)."

"Meu marido deu tumor no fígado e ele faleceu (Esperança)."

"A vó do meu filho por parte de pai, morreu com câncer de útero (Gratidão)."

Sendo assim, o câncer para Gratidão e Esperança pareceu ter uma relação muito forte com a morte ${ }^{18,19,28}$, como é possível perceber pelas lembranças da morte de parentes ou de conhecidos.

Para Esperança o câncer também é uma doença traiçoeira.

"Eu acho que o câncer é uma doença muito traiçoeira, porque quando você pensa que tá boa ele pode manifestar em outro lugar (Esperança)."

Sobre o momento específico da recidiva, as mulheres podem apresentar ansiedade antecipatória e pensamentos intrusivos ${ }^{14}$, baseados na concepção incurável do câncer, considerado uma doença que pode se disseminar a qualquer momento e atingir qualquer parte do corpo.

Nessa temática também são apresentadas como as entrevistadas, que moram no interior de Goiás, a uma distância de aproximadamente $320 \mathrm{~km}$ do local de realização do tratamento, se relacionam com esse distanciamento. Ao serem indagadas sobre como é o acesso geográfico às terapêuticas para o câncer, percebe-se que o percurso não facilita o tratamento, sendo este momento caracterizado como um fator estressante.

"Se eu vou amanhã hoje eu fico com uma depressão tão grande, eu fico ruim, a viagem é difícil (...) e chega aqui cansada é um sofrimento (Força)." 
"Tem que viajar muito, porque você vai consulta, depois marca a quimioterapia, tem que voltar pra fazer a quimioterapia, tem exames que tem que ser feito lá (Esperança)."

“Nossa, é cansativo demais! (...) é desconfortável, é muito difícil (Gratidão)."

As falas evidenciam que o tratamento altera a rotina das entrevistadas e as viagens contribuem significativamente para essas mudanças limitando a autonomia das participantes, sendo ainda necessária a incorporação da ajuda de outras pessoas para a obtenção de alguns cuidados, como podemos acompanhar nas falas de Gratidão e Força:

“Ele (marido) ficou oito dias sem trabalhar, ele colocava comida na minha boca, me levava ao banheiro, me dava banho (Gratidão)."

"Agora tem uma irmã minha aqui comigo (Força)."

O tratamento pode aproximar a família cujo membro está doente em virtude da necessidade de cuidados do ente querido adoecido, bem como para a realização das atividades domésticas rotineiras ${ }^{15}$. Contudo, o casal cuja esposa está realizando tratamento para seu câncer também pode ter alterações em sua sexualidade ${ }^{38,39}$, como se pode visualizar na fala a seguir:

"Mudou com meu esposo, mudou foi tudo e agora é cada um separado, porque ficou difícil (Força)."

Ainda em relação ao tratamento, Gratidão e Força continuam a relatar sobre a ausência de autonomia vivenciada nessa fase.

“Já não consigo fazer, nem meus bordados, isso tudo a gente sente falta (Gratidão)."

"Cuidava da casa, hoje não posso fazer mais nada (Força)."

Nos discursos das entrevistadas é perceptível o sofrimento que a falta de autonomia produz diante do impedimento de realização do trabalho tanto doméstico quanto fora do lar, principalmente para Força e
Gratidão, os quais eram centrais em seus cotidianos conferindo-Ihes ganho financeiro e status social ${ }^{23}$, o que aponta o câncer como uma doença que implica em diversas perdas ${ }^{8}$.

Portanto, as mulheres jovens entrevistadas neste estudo, ao responderem às indagações sobre as repercussões do diagnóstico de câncer de mama, relataram sentimentos negativos de perda e mudanças substanciais em suas vidas. Isso parece demonstrar que o câncer pode de fato alterar significativamente a rotina da vida de mulheres acometidas por essa enfermidade, bem como incentivar o diálogo com a religiosidade como possibilidade de enfrentamento dessa problemática, que é o descobrir-se com câncer.

\section{CONSIDERAÇÕES FINAIS}

Como foi observado nos resultados deste trabalho, as mulheres jovens, ao se depararem com o diagnóstico de câncer de mama sentem medo da morte e um grande choque, assim como as mulheres mais velhas que experienciam a doença, demonstrando dessa forma que o câncer ainda é uma doença carregada de sentidos negativos, e que pode alterar significativamente 0 cotidiano de mulheres por ela acometidas independentemente da faixa etária.

O estudo constatou que a mulher jovem valoriza a saída feminina para o mercado de trabalho, assim como o papel de cuidadora do lar, dos filhos e do marido, no entanto, observou-se que o câncer de mama limitou a continuidade de tais papéis, ocasionando sofrimento frente à perda da autonomia, assim como a necessidade de mudança nos planos de trabalho, lugar de moradia e comprometimento na vaidade. Quanto ao tratamento, observou-se a aproximação de cuidadores, mas também afastamentos, medos e dificuldades, sendo que para lidarem com todo o sofrimento decorrente da chegada do câncer, as participantes estabeleceram, preferencialmente, uma relação com a religiosidade.

O presente estudo, tendo sido desenvolvido baseado nos discursos de mulheres jovens que receberam 0 diagnóstico de câncer de mama, contribuiu focado apenas na perspectiva da pessoa doente. Sendo assim, outros estudos podem ser realizados na tentativa de ampliar a compreensão de mulheres jovens com câncer 
de mama em sua relação com a família e outros cuidadores, por exemplo.

Contudo, este trabalho também pode oferecer subsídios para a intervenção nessa população como, por exemplo, no auxílio para a construção de possibilidades de autonomia mesmo em meio às impossibilidades físicas impostas pela enfermidade. Além disso, os dados mostram ainda a necessidade de políticas públicas capazes de construir espaços de cuidado em oncologia mais próximos da população doente, visando a diminuição do sofrimento na realização das terapêuticas para o câncer.

\section{AGRADECIMENTOS}

Ao Prof. Dr. Tales Vilela Santeiro, pela leitura e considerações relevantes ao manuscrito.

\section{REFERÊNCIAS}

1. Brasil. Instituto Nacional do Câncer. Estimativa da incidência e mortalidade por câncer no Brasil. [dados na internet]. [acessado 2014 abr 29]. Disponível em: http://www.inca.org.br

2. Brasil. Ministério da Saúde. Cadernos de Informações de Saúde. [dados na internet]. [acessado 2012 nov 3]. Disponível em: http://www2.datasus.gov.br/DATASUS/ index.php.

3. Fundação do Câncer. Relatório Anual. Rio de Janeiro; 2010. p. 4-42.

4. Maluf MFM, Mori LJ, Barros ACSD. O impacto psicológico do câncer de mama. Rev Bras Cancerol. 2005; 51(2):14954.

5. Caetano AE, Grandim CVC, Santos LES. Câncer de mama: reações e enfrentamento ao receber o diagnóstico. Rev Enferm 2009; 17(2):257-61.

6. Panzini RG, Bandeira DR. Coping (enfrentamento) religioso/espiritual. Rev Psiq.Clín. 2007; 34(1):126-35.

7. Cangussu RO, Soares TBC, Barra AA, Nicolato R. Sintomas depressivos no câncer de mama: inventário de depressão de Beck - Short Form. JBras Psiquiatr 2010; 59(2):106-10.

8. Angerami-Camon VA, organizador. Psicologia da saúde: um novo significado para a prática clínica. São Paulo: Pioneira Thomson Learning; 2003.

9. Araújo IMA, Fernandes AFC. O significado do diagnóstico do câncer de mama para a mulher. Esc Anna Nery Rev Enfermagem 2008; 16(1):27-33.

10. Magalhães IS. Entre a casa e o trabalho: a transmissão geracional do feminino [dissertação]. Rio de Janeiro (RJ): Pontifícia Universidade Católica do Rio de Janeiro; 2010.

11. Sousa AS. Câncer de mama: representações e medos [monografia]. Fortaleza: Departamento de Enfermagem; 2000.

12. Makluf ASD, Dias RC, Barra AA. Avaliação da qualidade de vida em mulheres com câncer da mama. Rev Bras Cancerol. 2006; 52(1):49-58.

13. Segal SM. Mastectomia: mantendo sua qualidade de vida após o câncer de mama. Rio de Janeiro: Record; 1995.
14. Silva G, Santos MA. Estressores pós-tratamento do câncer de mama: um enfoque qualitativo. Rev Latino-Am. Enfermagem 2010; 18(4):688-95.

15. Ferreira CB. Sentidos construídos para o relacionamento conjugal na vivência do câncer de mama feminino [tese]. Ribeirão Preto: Escola de Enfermagem de Ribeirão Preto; 2007.

16. Aratangy LR. $O$ anel que tu me deste: o casamento no divã. São Paulo: Artemeios; 2007.

17. Ferreira CB, Almeida AM, Rasera EF. Sentidos do diagnóstico por câncer de mama feminino para casais que o vivenciaram. Interface - Comunicação, Saúde, Educação 2008; 12(27):863-71.

18. Brasil. Instituto Nacional do Câncer. Pesquisa de opinião pública dos brasileiros sobre o câncer. [dados na internet]. [acessado 2013 fev 9]. Disponível em: http://www.inca.org.br

19. Sant’anna BD. A mulher e o câncer na história. In: Gimenez MGG, organizadora. A mulher e o câncer. Campinas: Psy; 1997. p. 43-70.

20. Kelly-Anne P, Richard HO, Graham GG, Gillian S.D, Carmel A, John LH, Roger LM. Psychosocial factors and survival of young women with breast cancer: a populationbased prospective cohort study. J Clin Oncol 2008; 26(28):4666-71.

21. Peate $M$, Meiser B, Friedlander M, Zorbas $H$, Rovelli $S$, Sansom-Daly, U Sangster J, Hadzi-Pavlovic D, Hickey M. It's now or never: fertility-related knowledge, decisionmaking preferences, and treatment intentions in young women with breast cancer-an australian fertility decision aid collaborative group study. J Clin Oncol 2011; 13(1):1670-7

22. Howard-Anderson J, Ganz PA, Bower JE, Stanton AL. Quality of life, fertility concerns, and behavioral health outcomes in younger breast cancer survivors: a systematic review. J Natl Cancer Inst 2012; 104(5):386-405

23. Santos DB, Vieira, EM. Imagem corporal de mulheres com câncer de mama. Ciênc Saúde Colet 2011;16(5):2511-22.

24. Gergen KJ. The social constructionist movement in modern psychology. Am Psychol 1985; 40(3):266-75.

25. Spink MJ, Medrado B. Práticas discursivas e produção de sentidos no cotidiano: aproximaç̃̃es teóricas e metodológicas. São Paulo: Cortez; 2000.

26. Aquino VV, Zago MMF. O significado das crenças religiosas para um grupo de pacientes oncológicos em reabilitação. Rev. Latino-am. Enfermagem 2007;15(1):427.

27. Sontag S. Doença como metáfora, aids e suas metáforas. São Paulo: Companhia das Letras; 2007.

28. Santos GC, Gonçalves LLC. Mulheres mastectomizadas com recidiva de câncer: o significado do novo ciclo de quimioterapia. R Enfermagem UERJ 2006; 14(2):239-44.

29. Gomes R, Skaba MMVF, Vieira RJS. Reinventando a vida: proposta para uma abordagem sócio-antropológica do câncer de mama feminina. Cad. Saúde Pública 2002; 18(1):197-204.

30. Avelar EA, Faria LCM. Ser mulher na contemporaneidade: contribuições da teoria no imaginário social. Vertentes 2007; 29:111-7.

31. Pelegrini J, Martins NS. A história da mulher no trabalho: da submissão as competências. Um resgate histórico e as gestoras lajeadenses neste contexto. Rev Dest Acadêmicos 2010; 2(2):57-66

32. Bruschini MCA. Trabalho e gênero no Brasil nos últimos dez anos. Cadernos de Pesquisa 2007; 37(132):537-72.

33. Mayan MJ. Una Introducción a los métodos qualitativos: módulo de entrenamento para estudiantes y profesionales. 2001. [página da internet]. [acessado 2012 Jan 21]. 
Disponível em: www.ualberta.ca/ iiqm//pdfs/ introduccion.pdf.

34. Núcleo Regional de Combate ao Câncer da Cidade de Jataí Goiás. Histórico. [página da internet]. [acessado 2013 Jun 29]. Disponível em: http://www.nucleodocancerdejatai.com.br

35. Spink MJP. Desvendando as teorias implícitas: uma metodologia de análise das representações sociais. In: Guareschi P, Jovchelovitch S, organizadores. Textos em representações sociais. Petrópolis: Vozes; 2000. p. $117-$ 45

36. Mcnamee S, Hosking DM. Research and social change: a relational constructionist approach. New York: Routledge; 2012.

37. Teixeira JJV, Lefèvre F. Religiosidade no trabalho das enfermeiras da área oncológica: significado na ótica do discurso do sujeito coletivo. Rev Bras Cancerol. 2007; 53(2):159-66.

38. Gradim CVC. Sexualidade de casais que vivenciaram o câncer de mama [tese]. Ribeirão Preto: 2005. Escola de Enfermagem de Ribeirão Preto; 2005.

39. Picard L, Dumont S, Gagnon, P, Lessard, G. Coping strategies among couples adjusting to primary breast cancer. J Psychosoc Oncol. 2005;23(2-3):115-35.

\section{Endereço para correspondência:}

Isabella Barros Rabelo Gontijo

SQN 409, Bloco L, Apto. 207

Brasília/DF - CEP 70857-120

Telefone: +556481251713

E-mail: isabellagontijo1@gmail.com 